\title{
Que ações didáticas escolher diante de erros de alunos em problemas matemáticos?
}

\section{What didactic actions to choose when facing students' errors in mathematics problems?}

\author{
Maria Lucia Faria Moro ${ }^{1}$ \\ Maria Tereza Carneiro Soares ${ }^{2}$ \\ Alina Galvão Spinillo ${ }^{3}$
}

\section{Resumo}

O estudo descreve as ações didáticas que doze professores e doze futuros professores de matemática propõem para corrigir erros antes identificados de alunos do ensino fundamental em seis problemas de estrutura multiplicativa (produto de medida, isomorfismo de medida). Examina também se há relação entre o tipo de ação didática proposta e o tipo de erro identificado. Cada participante passou por uma entrevista semiaberta e os dados obtidos foram audiogravados. Os resultados mostram que professores e futuros professores propõem certa variedade de ações didáticas, com diferenças entre os dois grupos que variam quantitativamente conforme o tipo de problema. Já os sinais, pouco consistentes, de relação entre os tipos de ação didática e os tipos de erro identificado parecem variar, não exclusivamente pela formação e a experiência profissional, mas por alguma interação dessa variável com o tipo de problema. Implicações para a formação docente são discutidas.

Palavras-chave: Ações didáticas e tipos de erros em problemas multiplicativos; interpretação de professores; professores e futuros professores de matemática.

\begin{abstract}
The study describes the didactic actions proposed by twelve mathematics teachers and twelve pre-service teachers when facing errors on problems of multiplicative structure (product of measures and isomorphism of measures) committed by elementary school students. It also examines if there is a relationship between the type of didactic action proposed and the type of error identified. Each participant gave a semi-structured interview and the data was audio recorded. Results show that teachers and pre-service teachers proposed a variety of didactic actions; however, there are differences between both groups, which may vary quantitatively according to the type of the problem. In addition, the few consistent signs of a relationship between the type of didactic actions and the type of the identified errors may vary, not exclusively for the teachers' training and their experience, but also for some interaction between that variable with the type of problem. Implications for teachers' professional training are discussed.
\end{abstract}

\footnotetext{
${ }^{1}$ Doutora em Psicologia da Educação (PUCSP), professora titular aposentada do Departamento de Educação da Universidade Federal do Paraná (UFPR), Curitiba, Brasil. E-mail: mlfmoro@sul.com.br

${ }^{2}$ Doutora em Educação (USP), professora associada do Departamento de Planejamento e Administração Escolar da Universidade Federal do Paraná (UFPR), Curitiba, Paraná, Brasil. E-mail: mariteufpr@gmail.com

3 Doutora em Psicologia (Universidade de Oxford), professora titular do Departamento de Psicologia da Universidade Federal de Pernambuco (UFPE), Recife, Pernambuco, Brasil. E-mail: alinaspinillo@ hotmail.com
} 
DOI: http://dx.doi.org/10.20396/zet.v25i3.8649678

Keywords: Didactic actions and types of errors in multiplicative problems; teachers' interpretation; Mathematics teachers and pre-service teachers.

\section{Introdução}

O presente estudo dá continuidade a uma pesquisa anterior (Spinillo, Soares, Moro \& Lautert, 2016), cujo objetivo era examinar como professores e futuros professores de matemática interpretavam os erros de alunos do ensino fundamental ao resolverem problemas de estrutura multiplicativa. Os resultados permitiram identificar que os participantes categorizavam os erros conforme as seguintes categorias: conceituais (incompreensão das relações multiplicativas em jogo), linguísticos (dificuldades de compreensão da linguagem do enunciado) e procedimentais (emprego de operação inadequada). Contudo, embora conhecer essa categorização tenha sido importante, ficou em aberto a questão de que tipos de ações didáticas seriam propostos por futuros professores de Matemática e professores já licenciados quando diante de determinado tipo de erro (com vistas a superá-lo). Assim, este é o objetivo da presente investigação que procura acrescentar novas informações a respeito de como os erros dos alunos são tratados no contexto de ensino-aprendizagem da matemática.

Importante lembrar a inegável relevância de se conhecer como professores interpretam os erros dos alunos de diferentes níveis de ensino, sendo esta questão investigada, por exemplo, em estudos como os de Cury (2007), com foco no ensino superior. Porém, embora igualmente importante, pouco se sabe que ações didáticas o professor propõe ao se deparar com os erros dos alunos. Que ações seriam sugeridas? Essas ações variariam conforme a experiência do professor (professores e futuros professores)? Variariam conforme o tipo de problema resolvido pelo aluno? E teriam as referidas ações alguma relação com o tipo de erro antes identificado?

Dando continuidade e aprofundando o conhecimento sobre esse tema, o presente estudo tem como objetivos: a) descrever e analisar o tipo de ação didática que futuros professores e professores de matemática propõem para que alunos do ensino fundamental superem os erros expressos na solução de problemas de produtos de medidas e de isomorfismo de medidas; b) verificar se há alguma relação entre os tipos de ação didática propostos e os tipos de erros descritos nos problemas mencionados.

A relevância do modo como professores colocam o erro em evidencia durante a formação inicial de professores de Matemática tem sido apontada como fundamental, implicando diretamente suas futuras ações didáticas. Pesquisas sobre o tratamento dado ao erro por professores de cursos de Licenciatura em Matemática, portanto, os diretamente responsáveis pela formação de futuros professores, apontam para a prevalência de uma concepção de que o erro deve ser eliminado, não sendo encontrada distinção entre a forma de se lidar com os erros (Cury, 1994), sendo a única forma a de fazer um "reforço" do conteúdo até que a resposta do aluno reproduza o ensino do professor (Fischer, 2008). Alinhados à hipótese de que esta perspectiva revela a aceitação tácita de uma concepção absolutista da 
DOI: http://dx.doi.org/10.20396/zet.v25i3.8649678

Matemática como ciência exata, constituída de verdades eternas que não admitem suposições, as referidas pesquisadoras reiteram possíveis explicações do por que o professor formador, como também futuros professores e professores por ele formados, não tomam ou têm dificuldade em tomar o erro como objeto de discussão, analisando com o aluno as dificuldades expressas nas respostas às tarefas propostas.

Oposta a esta concepção absolutista, há outra, praticamente inexistente em professores das disciplinas de conteúdo matemático nas Licenciaturas (Cury, 1994; Fischer, 2008): uma concepção falibilista da Matemática (Lakatos, 1976) a que aceita que a produção do conhecimento matemático, assim como a de qualquer outro conhecimento, não está isenta de erros, mesmo tendo atingido o mais alto nível de formalização. Assim, se a descoberta de inconsistências teóricas é considerada motor para o desenvolvimento e aprimoramento de qualquer ciência, a identificação e análise dos caminhos que levam ao erro poderiam favorecer ao professor de Matemática ou ao que ensina Matemática, outro modo de lidar com os erros dos alunos, tomando desde os anos iniciais de escolarização as respostas deles como objeto de reflexão.

Estudos mostram que, algumas vezes, mesmo professores licenciados em Matemática e professores em exercício apresentam limitações em relação ao conhecimento matemático escolar a ser dominado pelos seus alunos. Borba, Pessoa e Rocha (2012), por exemplo, verificaram que, apesar de professores serem capazes de identificar a estrutura de diferentes tipos de problemas combinatórios apresentaram um conhecimento limitado desse conteúdo.

Resultado semelhante foi obtido por Castro-Rodriguez, Rico e Gómez (2012) ao verificarem que futuros professores do ensino básico atribuíram apenas à relação parte-todo papel crucial na concepção de fração. Segundo os autores, os futuros professores têm a ideia de que dividir um todo em frações é uma ação que produz partes, ação esta representada por uma figura seccionada, mas registraram que os entrevistados ignoravam outros significados que podem ser atribuídos a frações.

Também, Contreras, Carrillo, Zakaryan, Muñoz-Catalán e Cliemtn (2012), ao interpretarem as competências numéricas de estudantes espanhóis em cursos de formação de professores, surpreenderam-se com as dificuldades encontradas pela maioria deles, como: decompor quantidades não inteiras; comparar propriedades numéricas com números racionais; trabalhar flexivelmente com racionais e percentagens, e argumentar a respeito; explorar as propriedades das operações básicas e de suas relações ao lidar com números racionais e cálculos a elas ligados.

Em geral, os estudos revelam o quanto é deficiente a compreensão matemática dos candidatos a professores. Recomendam, então, um diagnóstico no início da formação para, não só conscientizar os estudantes de seus limites, mas também para superá-los. A formação profissional básica dos futuros professores e a formação continuada dos professores em exercício precisam prever conhecimentos que os auxiliem a analisar e tomar decisões sobre 
DOI: http://dx.doi.org/10.20396/zet.v25i3.8649678

seus erros para que possam identificar os erros dos alunos e os utilizar como ferramenta didática.

Ao conceber o erro como estratégia ou ferramenta didática, um professor que ensina matemática poderá dele inferir formas diversas de o aluno raciocinar ao executar uma tarefa, particularmente quando resolve problemas matemáticos (e.g. Pinto, 2000). Assim, poderá propor situações de ensino adequadas à superação de dificuldades específicas (e. g., Astolfi, 1999; Bessot, 1980; Borasi, 1996; Gitirana, Campos, Magina \& Spinillo, 2014; Spinillo, Pacheco, Gomes \& Cavalcanti, 2014).

Pesquisas no campo da didática da matemática francesa (e.g. Brousseau, 1998; Vergnaud, 2014; Chevallard, 1985) levaram à expressiva produção sobre a importância do verdadeiro e do falso nas classes de matemática (Margolinas, 1993). Esse tipo de produção sublinha, por exemplo, as singularidades e as oposições entre validação e avaliação no contexto da teoria das situações didáticas. Na avaliação emite-se um julgamento conclusivo conforme alguns critérios tanto sobre os caminhos seguidos na solução (o modo de solucionar a questão), quanto sobre o resultado matemático apresentado (no caso, a identificação do erro).

Durante a avaliação é preciso acompanhar os efeitos da análise que o aluno faz de sua produção para que tome consciência do modo como interpretou o discurso matemático do professor. $\mathrm{O}$ aluno deve se interessar prioritariamente por aquilo que, no discurso do professor, destaca o saber matemático, tendo um olhar crítico sobre sua solução. $O$ aluno que assume apenas reproduzir o que o professor ensina, restringe muito sua aprendizagem, podendo não modificar seus resultados escolares. Ao escolher que resolverá "como o professor", ele sobreviverá na escola sempre que for necessário responder com o processo padrão de solução, mas poderá não desenvolver sua capacidade para: ler e interpretar textos; envolver-se com as possíveis soluções; criar representações próprias ao identificar as sutilezas de cada situação a ele apresentada.

Moro e Soares (2006) descreveram a natureza e o nível de integração de duas professoras, analisando as mudanças de compreensão que elas expressaram ao avaliar as realizações de seus alunos em situações de adição-subtração. A referida integração sinalizou mudanças na forma de as professoras organizarem aspectos de seu ensino, especialmente: a necessidade de análise interligada dos resultados do aprender dos alunos com as formas de ensinar os conteúdos, algo favorecido pela participação das professoras na pesquisa; e, quanto à formação continuada docente, o significado da tomada de consciência dos resultados de seu fazer pedagógico para a progressão de seus conhecimentos profissionais.

Koch e Soares (2005) acompanharam a análise de uma professora de ensino fundamental dos erros de alunos na solução de problemas de estrutura aditiva. A professora descreveu os seguintes aspectos da produção dos alunos: tipos de notação em problemas de estrutura aditiva; forma de combinar os dados do problema e domínio dos conteúdos 
DOI: http://dx.doi.org/10.20396/zet.v25i3.8649678

envolvidos. Mas ela teve dificuldade nessa interpretação pela falta de conhecimentos sobre as formas de raciocinar subjacentes às notações dos alunos.

Por outro lado, os resultados do estudo sobre categorias de erros a problemas de estrutura multiplicativa, tal como vistos por futuros professores e professores (Spinillo, Soares, Moro \& Lautert, 2016), apontam peculiaridades interessantes quando olhado o tipo de problema: foram identificados como conceituais, sobretudo os erros nos problemas de produto de medidas, e como linguísticos ou conceituais, os erros nos problemas de isomorfismo de medidas. Assim, parece que formação e experiência profissionais não seriam condições estritamente suficientes na interpretação dos tipos de erros de alunos. Mas a associação dos tipos de problemas às formas de expressão das soluções e/ou às formas de enunciar os problemas mostrou-se relevante à discriminação dos erros. Isto sugere que quanto mais numerosas e variadas forem as formas de expressão das soluções dos alunos (escritas ou orais), mais indícios dos processos cognitivos dos alunos em jogo na solução tornam-se acessíveis a futuros professores e professores, os quais teriam, assim, mais elementos para interpretar aqueles erros.

Dada a relevância do tema para a prática docente, esses resultados anteriores fizeram emergir as duas questões seguintes a serem examinadas no presente estudo: que ação didática professores e futuros professores propõem para auxiliar os alunos a superar os erros cometidos ao solucionarem problemas de estrutura multiplicativa? Existiria alguma relação entre o tipo de ação didática proposta e o tipo de erro identificado?

\section{Método}

Os participantes formaram dois grupos. O Grupo 1 era constituído por 12 futuros professores (FP) cursando licenciatura em matemática; e o Grupo 2, por 12 professores (P) com licenciatura em matemática que ensinavam em turmas do $3^{\circ}$ ao $5^{\circ}$ ano do Ensino Fundamental em escolas públicas e particulares de grande região metropolitana.

Os participantes foram individualmente entrevistados por meio de um interrogatório de estilo clínico-crítico em única sessão áudio gravada. Foram-lhes apresentadas, uma por vez, seis cartelas, cada uma contendo o enunciado de um problema e um procedimento incorreto de resolução. Em três cartelas os problemas eram de produto de medidas (PM) (Apêndice A) e, nas outras três, de isomorfismo de medidas (IM) (Apêndice B), segundo classificação proposta por Vergnaud $(1983 ;$ 2014). A ordem de apresentação das cartelas foi aleatória, decidida por sorteio para cada participante.

O participante era informado que as soluções incorretas apresentadas haviam sido de fato produzidas por alunos do Ensino Fundamental . Era ele então solicitado a interpretar os erros expressos em cada solução e a propor uma ação didática que contribuísse para superar aquele erro. A pergunta-base que norteava a entrevista era: "Se você fosse o (a) professor (a) deste aluno, o que faria para ajudá-lo a superar este tipo de erro?". Às vezes, perguntas 
DOI: http://dx.doi.org/10.20396/zet.v25i3.8649678

adicionais eram feitas, para esclarecer a resposta e as justificativas dadas pelo participante, como previsto em entrevistas do tipo indicado.

\section{Resultados}

Os resultados são expostos em dois momentos distintos, mas complementares. Primeiro, são descritos e exemplificados os diferentes tipos de ações didáticas propostas pelos entrevistados e sua distribuição conforme os grupos de participantes e os tipos de problemas investigados. Em um segundo momento, é analisada a existência de relação entre os tipos de ações didáticas e os tipos de erro identificados pelos entrevistados.

\section{Os diferentes tipos de ações didáticas propostos.}

Um total de 144 respostas foi analisado, permitindo identificar uma variedade de ações didáticas que foram agrupadas em diferentes tipos a partir de discussão e acordo entre três juízes. Os diversos tipos são descritos e exemplificados a seguir"

Tipo 1 (representação gráfica): a ação proposta consiste em trabalhar com o aluno uma representação gráfica (icônica ou pictográfica) em que as relações multiplicativas necessárias para a solução apropriada do problema sejam explicitadas para, assim, ele compreender a razão de a operação matemática ser pertinente. Exemplo 1 (Problema 2 no Apêndice A):

FP: Ia ser difícil explicar isso pra ele (aluno)... Acho que aqui a gente tinha que tentar pelo desenho, também..., eu tinha que apelar pro desenho e... fazer, colocar as outras coisas embaixo aqui, talvez, né? ... porque uma só, pra talvez evitar, escolher uma, sobrariam duas coisas... e aí tentar induzir ele a multiplicar, tentar, que multiplicando ia sair o resultado. Acho que por aí, mas também, pelo desenho. Acho que o fato de ter só os três aqui confundiu ele.

Tipo 2 (concretização): a ação proposta consiste em levar o aluno a representar as relações multiplicativas necessárias à solução por meio de material manipulativo e assim, identificar a operação pertinente a ser empregada. Exemplo 2 (Problema 4 no Apêndice B):

P: (ao mesmo tempo) Se eu fosse a professora... faria bem isso... Tem que ser uma simulação porque, de alguma forma, ele fez um cálculo que absolutamente não, demonstra que ele não entendeu nada do que está ali. Então, eu preciso começar do começo que é a interpretação. Imaginar que ele tem trinta e dois comprimidos, como que funciona, como é que o médico faz, é tomar quatro comprimidos por dia; como que a gente vai fazendo? Então, vamos anotar, fazer com a turma toda; sabe, simular. $\mathrm{E}$, depois, a gente trabalha alguma outra situação. Mas nesse caso aqui, ele não

\footnotetext{
${ }^{4}$ Nas passagens das entrevistas que servem de exemplos, as falas são assim identificadas: E: entrevistadora; FP: futuro professor e P: professor.
} 
DOI: http://dx.doi.org/10.20396/zet.v25i3.8649678

entendeu absolutamente nada do que ele deveria fazer, né?... Ele operou com os numerais e eu vejo muito isso. Eles fazem muito isso, pega os valores ali e faz um cálculo.

Tipo 3 (explicação oral): a ação proposta consiste em o professor fornecer oralmente exemplos para ilustrar as relações necessárias para a resolução do problema, havendo casos em que se requer do aluno reinterpretação daquelas relações para, então, aplicar a operação pertinente. Exemplo 3 (Problema 6 no Apêndice B):

E: E se você fosse a professora dele, como é que você interviria aí nesta história pra ele sair dessa enrascadinha aí?

P: Trabalhar realmente. Pegar o problema, ver qual é a pergunta do problema, o que é que tá trabalhando o problema, quanto que precisa pra fazer um bolo: "Vamos calcular junto: Um bolo são quantos ovos? E se eu precisar pra cinco bolos?". Trabalhar todo esse raciocínio com ele. Retomar o conceito mesmo de proporção.

Tipo 4 (exercícios): a ação proposta consiste em levar o aluno a realizar outros problemas semelhantes àquele que resolveu de forma equivocada. Exemplo 4 (Problema 4 no Apêndice B):

FP: Ah! Também assim, eu ia dar uns três exercícios, ia dar a matéria, ia dar os exercícios, depois eu ia passar carteira por carteira, para ver se eles estão fazendo.

E: Olhar o que eles estão fazendo?

FP: O que eles estão fazendo. Às vezes eu vejo esses casos assim. Se eu visse, eu ia, eu recolheria, daí eu ia ter que dar explicação de soma e de divisão, ter que explicar de novo, não tem outro jeito, porque desse jeito aqui não deu certo. E ia assim até eles entenderem, ou fazer alguma outra coisa nova pra eles que eles entendessem.

Tipo 5 (leitura): a ação consiste em fazer o aluno ler novamente o enunciado do problema para que o reinterprete, sendo orientado pela professora nessa leitura para que ocorram a identificação e/ou compreensão das relações pertinentes à solução. Exemplo 5 (Problema 5 no Apêndice B):

E: Se você fosse a professora dele, que tipo de coisa você faria pra ele mudar de jeito, ai?

P: É, pra ele é, conseguir entender? ... Bom, a primeira coisa que eu acho. É que não ficou claro pra criança o significado do texto. Ele não entendeu. Então, a primeira coisa que eu tenho que ter certeza é de que ele tenha entendido, é discutir o texto com ele. Eu discutiria, faria ler, ia perguntar pra ele o que significa aquele seis... O que é que são os dois, quanto que a Sandra comprou, onde que tinha... discutir o problema, até que ele entenda o que está acontecendo ali. Porque se, quando a gente lê rápido assim mesmo, você não consegue entender, né? ... Assim, pensar. Então precisa uma discussão, preciso garantir que ele tenha interpretado direitinho e isto não invalida... de nenhuma forma o resultado dele, né? O desempenho dele. 
DOI: http://dx.doi.org/10.20396/zet.v25i3.8649678

Tipo 6 (genérica): é proposta alguma ação, às vezes sem qualquer relação com o erro apresentado ou há recomendação ampla de diversas ações didáticas. Por exemplo: revisar conteúdos de anos escolares anteriores, realizar um atendimento extraclasse, reformular o enunciado do problema. Exemplo 6 (Problema 6 no Apêndice B):

FP: Ou... eu não sei o que eu faria também com isso.

E: Pois é, o que você faria se fosse o professor? Alguma, algum caminho pra tomar com ele?

FP: Porque também dá pra ver que eles são muito fracos, meu Deus. A professora vai ter que, tipo, recuperar operações muito básicas pra conseguir prosseguir com o trabalho... Eu acho que está faltando muito a interpretação do problema, né? ... A interpretação, não só simplesmente recolher os dados, assim...

E: Você trabalharia com a interpretação dele?

FP: Sim, eu acho que eu ia retomar todos os, os assuntos bem básicos porque, por essas duas questões, eles não estão sabendo fazer nada, né? Tá bem feia a situação.

E: Mas tem conserto? O professor consertaria?

FP: Sim, mas estaria bem atrasado, não é? ... Porque teria que passar, porque teria que passar o conteúdo de agora, e teria que estar passando as coisas que eles já deveriam de saber. Então, eu acho que é meio preocupante isto.

Importante mencionar que em raras ocasiões mais de um tipo de ação didática foi proposto. Quando isso ocorria, optou-se por categorizar a resposta dada como sendo de um tipo apenas, o enfatizado na fala do entrevistado.

Conforme a Tabela 1, os dados mostram haver diferenças entre professores e futuros professores quanto à predominância e à variação dos tipos de ações didáticas propostos.

Tabela 1: Frequências e percentuais (entre parênteses) de tipos de ação didática propostos por professores e futuros professores ${ }^{5}$.

\begin{tabular}{ccccccc}
\hline & Tipo 1 & Tipo 2 & Tipo 3 & Tipo 4 & Tipo 5 & Tipo 6 \\
\hline $\begin{array}{c}\text { Professores } \\
(\mathrm{n}=72)\end{array}$ & 23 & 13 & 15 & 3 & 18 & 0 \\
& $(31,9)$ & $(18)$ & $(21)$ & $(4,1)$ & $(25)$ & $(0,0)$ \\
$\begin{array}{c}\text { Futuros } \\
\text { professores }\end{array}$ & 24 & 11 & 28 & 3 & 3 & 3 \\
\hline & $(33,4)$ & $(15,3)$ & $(39)$ & $(4,1)$ & $(4,1)$ & $(4,1)$ \\
\hline
\end{tabular}

\footnotetext{
${ }^{5} \mathrm{O}$ valor de $n$ para cada grupo foi obtido multiplicando-se o número de participantes (12) pelo número de problemas apresentados (6).
} 
$(n=72)$

Nota: Tipo 1 (representação gráfica); Tipo 2 (concretização); Tipo 3 (explicação oral); Tipo 4 (exercícios); Tipo 5 (leitura) e Tipo 6 (genérica).

Os futuros professores concentram suas escolhas em representações gráficas (Tipo 1) e em explicações orais (Tipo 3). Já os professores propõem ações didáticas mais variadas (Tipo 1, 2, 3 e 5), embora também concentrem suas escolhas na representação gráfica. Importante notar que a leitura do enunciado do problema (Tipo 5) foi escolha rara entre os futuros professores $(4,1 \%)$, mas muito apontada pelos professores $(25 \%)$. E somente os futuros professores, embora em baixa frequência, têm escolhas de Tipo 6, as genéricas.

A Tabela 2 mostra as relações entre tipos de ações didáticas e os tipos de problemas.

Tabela 2: Frequências e percentuais (entre parênteses) de tipos de ações didáticas conforme tipos de problemas.

\begin{tabular}{ccccccc}
\hline & Tipo 1 & Tipo 2 & Tipo 3 & Tipo 4 & Tipo 5 & Tipo 6 \\
\hline IM & 20 & 16 & 17 & 3 & 13 & 3 \\
$(\mathrm{n}=72)$ & $(27,7)$ & $(22,2)$ & $(23,6)$ & $(4,1)$ & $(18)$ & $(4,1)$ \\
& & & & & & \\
PM & 27 & 8 & 26 & 3 & 8 & 0 \\
$(\mathrm{n}=72)$ & $(37,5)$ & $(11,1)$ & $(36,1)$ & $(4,1)$ & $(11,1)$ & $(0,0)$ \\
\hline
\end{tabular}

Nota: Tipo 1 (representação gráfica); Tipo 2 (concretização); Tipo 3 (explicação oral); Tipo 4 (exercícios); Tipo 5 (leitura) e Tipo 6 (genérica); IM (isomorfismo de medidas); PM (produto de medidas)

Cotejando-se tão somente os percentuais obtidos conforme os tipos de problema, temse que as ações de Tipo I (representação gráfica) e de Tipo 3 (explicação oral) foram sobretudo propostas para os problemas PM. Mas as ações de Tipo 2 (concretização) e as de Tipo 3 (leitura) foram mais escolhidas para os problemas IM do que para os PM.

A Tabela 3 ilustra este aspecto de forma mais detalhada, em relação a cada grupo de participantes. 
DOI: http://dx.doi.org/10.20396/zet.v25i3.8649678

Tabela 3: Frequências e percentuais (entre parênteses) de ações didáticas propostas conforme tipos de problemas para cada grupo de participantes.

\begin{tabular}{lcccccc}
\hline \multicolumn{7}{c}{ Professores (n=72) } \\
\hline & Tipo 1 & Tipo 2 & Tipo 3 & Tipo 4 & Tipo 5 & Tipo 6 \\
\hline IM & 9 & 9 & 8 & 0 & 10 & 0 \\
& $(12,5)$ & $(12,5)$ & $(11,1)$ & $(0,0)$ & $(13,8)$ & $(0,0)$ \\
PM & 14 & 4 & 7 & 3 & 8 & 0 \\
& $(19,4)$ & $(5,5)$ & $(9,7)$ & $(4,1)$ & $(11,1)$ & $(0,0)$ \\
\hline \multicolumn{7}{c}{ Futuros professores $(\mathrm{n}=72)$} \\
& Tipo 1 & Tipo 2 & Tipo 3 & Tipo 4 & Tipo 5 & Tipo 6 \\
& 11 & 7 & & & \\
\hline IM & $(15,2)$ & $(9,7)$ & $(12,5)$ & $(4,1)$ & $(4,1)$ & $(4,1)$ \\
& 13 & 4 & 19 & 0 & 0 & 0 \\
PM & $(18)$ & $(5,5)$ & $(26,3)$ & $(0,0)$ & $(0,0)$ & $(0,0)$ \\
\hline
\end{tabular}

Nota: Tipo 1 (representação gráfica); Tipo 2 (concretização); Tipo 3 (explicação oral); Tipo 4 (exercícios); Tipo 5 (leitura) e Tipo 6 (genérica); IM (isomorfismo de medidas); PM (produto de medidas).

Entre os professores, a concretização (Tipo 2) é mais frequentemente escolhida para superar as dificuldades com os problemas IM do que para os problemas PM, tipo para o qual eles indicam sobretudo a representação gráfica (Tipo 1). Para os demais tipos de ações didáticas apontados pelos professores, os percentuais são muito próximos, sugerindo que tais ações seriam gerais, amplas, podendo ser adotadas frente a qualquer um dos dois tipos de problemas.

Para os futuros professores, a explicação oral (Tipo 3) e a representação gráfica (Tipo 1) aparecem mais atreladas aos problemas PM do que aos problemas IM. E, para este tipo de problema, a concretização (Tipo 2), por seu lado, tem percentual relativamente mais alto de escolhas do que para os problemas PM.

A notar que os dois grupos têm em comum indicar mais fortemente a concretização para problemas IM, mas não para problemas PM; e a representação gráfica, para os problemas PM. Mas, diversamente dos futuros professores, e ainda que em percentual não tão alto, os professores fazem a escolha do Tipo 5 (leitura do enunciado do problema) para os dois tipos de problemas.

Relação entre tipos de ações didáticas e tipos de erros identificados. 
DOI: http://dx.doi.org/10.20396/zet.v25i3.8649678

Para ilustrar o exame das possíveis relações entre tipos de ações didáticas e tipos de erros identificados são expostos, a seguir, trechos das entrevistas. A tipologia de erros adotada é a proposta por Spinillo, Soares, Moro e Lautert (2016), já registrada neste texto. Seguem exemplos de ações didáticas propostas frente aos tipos de erros mais frequentemente identificados:

Exemplo 7 (Problema 2 no Apêndice A): para o tipo de erro conceitual (decorrente de incompreensão pelo aluno das relações multiplicativas necessárias à solução do problema) é proposta ação didática do tipo 1, representação gráfica, especificamente, o desenho.

FP: Aqui eu acho que ele pensou que bastaria não..., fazer, ele colocar no desenho uma camiseta e uma calça de cada cor, e bastaria daí, estava certo. Ele não levou em conta aqui que estava cinco bermudas aí... Eu acho que faltou conteúdo pra ele mesmo assim, né? Ou, e também levando em conta a idade, acho que inclusive houve um erro aqui. Eu acho isto, porque eu acho que ele pensou que, pensou isto, né? Ele pensou errado, mas pensou isto.

E: Pensou isto?

FP: Colocando uma coisa "diferente" aqui.

E: Mas que "diferentes" são estas?

FP: Essa foi a que ele pensou, ele não pensou que se ele pegasse uma, uma das cinco bermudas, teria quatro escolhas diferentes, pra fazer ali. Se ele pegasse mais duas, teria três ainda, daí teria que usar o princípio da multiplicação, né? $\mathrm{E}$ isto, com certeza, ele não ia saber.

E: Se você fosse o professor dele, o que é que você faria?

FP: Ia ser difícil explicar isso pra ele. Acho que aqui a gente tinha que tentar pelo desenho, também, eu tinha que apelar pro desenho e fazer, colocar as outras coisas embaixo aqui, talvez, né? ... porque uma só, pra talvez evitar, escolher uma, sobrariam duas coisas... e aí tentar induzir ele a multiplicar, tentar, que multiplicando ia sair o resultado. Acho que por aí, mas também, pelo desenho...

Exemplo 8 (Problema 1 no Apêndice A): para o tipo conceitual é proposta ação didática do tipo 2 , concretização.

P: Ele imaginou que a pessoa... Ele não pensou em combinação. Ele pensou que a criança entra e sai, simples. Então, pra ele, quem entrou pela porta A, saiu pela 1, resolveu... quem entrou pela $A$, saiu pela 2 , quem entrou pela $B$, saiu pela 1 , pela porta 1. Então, eu acredito que ele não considerou como que uma pessoa pode entrar por A e sair por duas ao mesmo tempo. Ele não entendeu o que é que são possibilidades. Eu vejo isso, ele não entendeu o que são possibilidades. Falta conversar, quem sabe é, fazer na prática uma situação, numa sala de aula, duas portas, quais você pode sair, quais opções, trabalhar isso, porque ele não entendeu, ele imaginou que eram escolhas, e não possibilidades.

E: Então, se você fosse a professora. Você ia, por exemplo, fazer esse tipo de coisa?

P: É, eu ia fazer esse tipo de atividade, na prática [...] levantar, fazer, trocar com eles, fazer com que as crianças tentem fazer né, simulações [...] E ele entender que são 
DOI: http://dx.doi.org/10.20396/zet.v25i3.8649678

possibilidades: "Eu posso ir por aqui ou por aqui? Entro por aqui ou por aqui?". Dentro da própria escola...

Exemplo 9 (Problema 4 no Apêndice B): para o tipo de erro linguístico (decorrente de dificuldades em compreender a linguagem do enunciado do problema) é proposta ação didática do tipo 5 leitura do enunciado.

E: E se você fosse a professora, como é que você iria, o que é que você iria fazer com isso ai?

P: Como? E: Pra quebrar essa história aí?

P: Pra quebrar essa história? É, eu ia pedir pro aluno tentar se colocar no lugar da Ana, né? "Vamos pensar que você tenha tomado trinta e dois comprimidos." Eu iria pedir: "Bem, você tomou tantos dias, né"? E que, só que, tantos comprimidos, só que esses comprimidos, você tinha que tomar quatro comprimidos por dia. É isso mesmo?". Nessa situação, eu ia pedir pra que o aluno se colocasse no lugar de alguém que está tomando esses comprimidos. E, de novo, retornar no enunciado, retornar na interpretação das informações que são dadas. Eu faria essa intervenção até ele perceber que ele vai ter que dividir.

A Tabela 4 expõe as frequências e os percentuais dos tipos de ações didáticas conforme os tipos de erros, para os dois grupos de participantes. Constata-se ali que, para erros conceituais, os professores propõem, sobretudo, as ações didáticas seguintes: representações gráficas (Tipo 1), concretização (Tipo 2) e leitura do enunciado (Tipo 5). Para erros linguísticos, propõem representações gráficas (Tipo 1) e leitura (Tipo 5), e somente os professores escolhem a leitura do enunciado para esse tipo de erro. Quando diante de erros de procedimento, os professores tendem a sugerir representações gráficas. Tem-se que a representação gráfica é bastante escolhida para diversos tipos de erros e que o erro conceitual (o mais frequente), para os professores pode ser superado mediante ações didáticas distintas. 
DOI: http://dx.doi.org/10.20396/zet.v25i3.8649678

Tabela 4: Frequências e percentuais (entre parênteses) de ações didáticas propostas conforme tipos de erro em cada grupo de participante

\begin{tabular}{|c|c|c|c|c|c|c|}
\hline \multicolumn{7}{|c|}{ Professores $(n=72)$} \\
\hline & Tipo 1 & Tipo 2 & Tipo 3 & Tipo 4 & Tipo 5 & Tipo 6 \\
\hline Conceitual & $\begin{array}{c}13 \\
(18)\end{array}$ & $\begin{array}{c}12 \\
(16,6)\end{array}$ & $\begin{array}{c}9 \\
(12,5)\end{array}$ & $\begin{array}{c}2 \\
(2,7)\end{array}$ & $\begin{array}{c}13 \\
(18)\end{array}$ & $\begin{array}{c}0 \\
(0,0)\end{array}$ \\
\hline Linguístico & $\begin{array}{c}4 \\
(5,5)\end{array}$ & $\begin{array}{c}0 \\
(0,0)\end{array}$ & $\begin{array}{c}2 \\
(2,7)\end{array}$ & $\begin{array}{c}0 \\
(0,0)\end{array}$ & $\begin{array}{c}4 \\
(5,5)\end{array}$ & $\begin{array}{c}0 \\
(0,0)\end{array}$ \\
\hline Procedimento & $\begin{array}{c}3 \\
(4,1)\end{array}$ & $\begin{array}{c}1 \\
(1,3)\end{array}$ & $\begin{array}{c}2 \\
(2,7)\end{array}$ & $\begin{array}{c}0 \\
(0,0)\end{array}$ & $\begin{array}{c}1 \\
(1,3)\end{array}$ & $\begin{array}{c}0 \\
(0,0)\end{array}$ \\
\hline Não informado ${ }^{6}$ & $\begin{array}{c}3 \\
(4,1)\end{array}$ & $\begin{array}{c}0 \\
(0,0)\end{array}$ & $\begin{array}{c}2 \\
(2,7)\end{array}$ & $\begin{array}{c}1 \\
(1,3)\end{array}$ & $\begin{array}{c}0 \\
(0,0)\end{array}$ & $\begin{array}{c}0 \\
(0,0)\end{array}$ \\
\hline \multicolumn{7}{|c|}{ Futuros professores $(n=72)$} \\
\hline & Tipo 1 & Tipo 2 & Tipo 3 & Tipo 4 & Tipo 5 & Tipo 6 \\
\hline Conceitual & $\begin{array}{c}20 \\
(27,7)\end{array}$ & $\begin{array}{c}6 \\
(8,3)\end{array}$ & $\begin{array}{c}24 \\
(33,3)\end{array}$ & $\begin{array}{c}1 \\
(1,3)\end{array}$ & $\begin{array}{c}3 \\
(4,1)\end{array}$ & $\begin{array}{c}2 \\
(2,7)\end{array}$ \\
\hline Linguístico & $\begin{array}{c}0 \\
(0,0)\end{array}$ & $\begin{array}{c}2 \\
(2,7)\end{array}$ & $\begin{array}{c}2 \\
(2,7)\end{array}$ & $\begin{array}{c}0 \\
(0,0)\end{array}$ & $\begin{array}{c}0 \\
(0,0)\end{array}$ & $\begin{array}{c}1 \\
(1,3)\end{array}$ \\
\hline Procedimento & $\begin{array}{c}3 \\
(4,1)\end{array}$ & $\begin{array}{c}0 \\
(0,0)\end{array}$ & $\begin{array}{c}1 \\
(1,3)\end{array}$ & $\begin{array}{c}2 \\
(2,7)\end{array}$ & $\begin{array}{c}0 \\
(0,0)\end{array}$ & $\begin{array}{c}0 \\
(0,0)\end{array}$ \\
\hline Não informado & $\begin{array}{c}1 \\
(1,3)\end{array}$ & $\begin{array}{c}3 \\
(4,1)\end{array}$ & $\begin{array}{c}1 \\
(1,3)\end{array}$ & $\begin{array}{c}0 \\
(0,0)\end{array}$ & $\begin{array}{c}0 \\
(0,0)\end{array}$ & $\begin{array}{c}0 \\
(0,0)\end{array}$ \\
\hline
\end{tabular}

Nota: Tipo 1 (representação gráfica); Tipo 2 (concretização); Tipo 3 (explicação oral); Tipo 4 (exercícios); Tipo 5 (leitura) e Tipo 6 (genérica).

Ainda conforme a Tabela 4, já os futuros professores parecem priorizar a explicação oral (Tipo 3) para os erros conceituais e linguísticos. Os conceituais também são considerados superáveis pelo uso de representações gráficas. Frente a erros de procedimento, também são propostas representações gráficas (Tipo 1), tal como observado entre os professores.

\footnotetext{
${ }^{6}$ Tipo de erro não informado apareceu entre professores e futuros professores, o que indica que mesmo sem serem capazes de identificar o tipo de erro, os entrevistados propunham alguma ação didática. $\mathrm{O}$ exame das relações entre o tipo de erro não informado e o tipo de ação didática não foi esclarecedor, o que leva a direcionar a discussão dos dados da Tabela 4 para os demais tipos de erros efetivamente identificados.
} 
DOI: http://dx.doi.org/10.20396/zet.v25i3.8649678

De modo geral, os dados obtidos mostram que professores e futuros professores propõem uma variedade de ações didáticas, sem que haja uma relação evidente entre tipo de erro e tipo de ação didática. Porém, dada a variação das ações didáticas propostas e considerados os tipos de problema (IM e PM), parece haver mais diferenças do que semelhanças entre as escolhas apresentadas. Por exemplo, tomando-se em conjunto os dados das Tabelas 3 e 4: (i) para futuros professores, explicação oral tem percentual mais alto de escolha para erros conceituais em problemas PM, mas para os professores a concretização das situações tem percentual mais alto de escolha para erros conceituais em problemas IM; (ii) para professores, embora com menos escolhas, a leitura orientada do enunciado é mais lembrada para erros conceituais (problemas PM e IM) do que para os linguísticos; já futuros professores, escolhendo em baixa frequência a leitura orientada, o fazem para os erros conceituais em problemas IM, mas preferem a explicação oral no caso de erros linguísticos e somente em problemas IM; (iii) a escolha pela concretização para erros conceituais é mais acentuada para professores do que para futuros professores e ocorre sobretudo para problemas IM.

Alguns pontos acerca dos resultados merecem ser destacados. Por exemplo: (i) há forte escolha das representações gráficas para erros conceituais por futuros professores e professores, mas, para estes, somente no caso dos problemas PM. Cabe lembrar que estes problemas trazem desenhos nas soluções ou como parte do próprio texto; (ii) para erros de procedimento, de frequência baixa entre futuros professores e professores, aparecem tipos de escolha em comum, como as representações gráficas e as explicações orais, sobretudo, para problemas IM.

Logo, sinais de associação entre tipos de erros identificados e ações didáticas parecem materializar-se não apenas conforme a formação e a experiência profissional, em si, mas levando em conta o tipo de problema, consideradas as características do enunciado de cada um deles e da solução que a ele fora dada.

\section{Discussão e considerações finais}

Ao se indagar a professores e futuros professores de Matemática sobre o que fazer diante dos erros de alunos do $3^{\circ}$ ao $5^{\circ}$ ano do ensino fundamental na solução de problemas multiplicativos de produto de medidas e de isomorfismo de medidas foi possível constatar diferenças entre os dois grupos: futuros professores concentram opções pela representação gráfica e pela explicação oral; professores escolhem esses tipos, mas também a concretização e a leitura do enunciado do problema. E ações didáticas genéricas são escolhidas apenas por futuros professores.

Como explicar essas diferenças? Pesariam as diferenças de formação e de experiência entre os dois grupos de participantes? Uma resposta positiva a essa pergunta se faz viável se levarmos em conta: 
DOI: http://dx.doi.org/10.20396/zet.v25i3.8649678

a) a especificidade maior de escolhas dos professores no enfrentamento de erros, incluindo a relevância da compreensão do enunciado dos problemas, pelo aluno, por meio da leitura; em contraste, há a escolha de ações genéricas, algo exclusivo aos futuros professores, sugerindo não ter havido deles, então, alguma reflexão mais específica;

b) a relativa ênfase na escolha dos futuros professores pela explicação oral, modo mais tradicional de ensino, talvez se explique pela proximidade temporal de sua própria escolarização básica. É plausível esse argumento porque, muitas vezes, os futuros professores justificaram suas escolhas, lembrando-se de suas próprias experiências escolares.

Porém, formação e experiência profissional fariam alguma diferença nas escolhas entre os dois grupos de participantes somente por conta dos aspectos acima apontados? Cabe ir mais fundo nessa apreciação mesmo porque, em estudo anterior (Spinillo, Soares, Moro \& Lautert, 2016) formação e experiência profissionais não foram vistos como condições estritamente suficientes na interpretação dos tipos de erros de alunos.

Discutir sobre as escolhas dos tipos de ações didáticas conforme os tipos de problemas de estrutura multiplicativa cujas soluções incorretas foram focalizadas pode trazer outros elementos para se pensar sobre o lugar da formação e da experiência profissional nas escolhas didáticas.

Assim, que significação teria o fato de as ações didáticas escolhidas variarem conforme o tipo de problema considerado? Pode-se entender que:

a) a representação gráfica foi muito mais apontada para problemas de produto de medidas: tanto professores como futuros professores a viram como mais viável para lidar com as diferentes combinações de cada variável com cada valor de outra(s), na identificação de todos os possíveis casos em jogo (esgotar as combinações como esquema essencial de raciocínio para resolver problemas de produto de medidas);

b) por outro lado, sobretudo os futuros professores apostaram na eficiência da explicação oral como forma de deixar claro aos alunos aquelas possibilidades de combinação, modo este mais clássico, na tradição pedagógica, de fazer o ensino, em contraste com o trabalho com representações gráficas;

c) a concretização pode ter sido menos apontada para os problemas de produto de medidas porque tanto professores como futuros professores estariam entendendo que o uso de material manipulável não daria conta das complexas relações um para muitos que precisam ser estabelecidas para resolver aquele tipo de problema. Porém, esse tipo de ação didática pode ter sido mais apontado para problemas de isomorfismo de medidas porque, sobretudo professores estariam admitindo que a relação quaternária (Vergnaud, 2014) entre dois ou mais tipos de medidas, inerente aos problemas de isomorfismo de medidas, seria mais facilmente manipulável com materiais do que as relações um para muitos, específicas de problemas de produto de medida; 
DOI: http://dx.doi.org/10.20396/zet.v25i3.8649678

d) não menos importante, escolhida, sobretudo, por professores e para os dois tipos de problema, a leitura do enunciado denota atenção a essa dimensão dos problemas matemáticos: a interpretação textual pertinente pode ser vista como uma das condições necessárias para a compreensão progressiva das relações em jogo, evitando, assim, o emprego sem sentido de algoritmos nem sempre adequados, e dando significação ao processo de solução e ao resultado obtido.

Diante dessas considerações, haveria pontos de aproximação entre as escolhas de professores e futuros professores quanto às ações didáticas escolhidas conforme o tipo de problema, relativizando o papel stricto sensu da variável formação e experiência profissional. Por outro lado, há sinais de diferenças que fortaleceriam o papel daquela variável. Primeiro, diversamente dos professores, os futuros professores apostam mais nas explicações orais tradicionais (lembrar-se de marcas que esse tipo de ensino lhes deixou em sua escolarização básica), não ainda plenamente cientes das peculiaridades dos tipos de problemas para escolher outros tipos de ação. Segundo, também diversamente dos professores, os futuros professores quase que ignoram a leitura do enunciado como ação didática e para os dois tipos de problema. Logo, pode ser que formação e experiência profissional tenham falado a favor dos professores nesses aspectos, fazendo-os evitar as explicações orais e as formas genéricas.

A salientar que a representação gráfica foi mais escolhida do que a concretização, especialmente para os problemas de produto de medidas. Tem sido relevante, na literatura recente de educação matemática, o papel da representação na solução de problemas aritméticos complexos. Por exemplo, Vergnaud (2014) indica princípios que devem guiar a ação do professor para que o ensino não resulte apenas em treinamentos pouco eficazes. Dentre os princípios que envolvem essencialmente atividades de representação verbal e escrita, indispensáveis para orientar o aluno na análise aprofundada das relações e transformações em jogo, o autor recomenda que: "Em caso de insucesso, recorrer a uma reconstrução material e gesticulada da situação dada no enunciado e reestabelecer os elos entre a situação material e as representações que dela são feitas (enunciado, esquema, ...)" (p. 293).

O papel da formação e da experiência profissional nas interpretações e escolhas parece ficar mais claro quando examinadas as possíveis relações entre tipos de erros antes identificados (Spinillo, Soares, Moro \& Lautert, 2016) e os tipos de ação didática propostos. Embora não tenha sido observada relação clara entre tipos de erros e ações didáticas, os indícios observados a respeito são permeados pelo tipo de problemas, consideradas as características do enunciado e as das soluções dos mesmos.

Assim, poder-se-ia argumentar favoravelmente pela importância da formação e da experiência profissional se olhados os seguintes resultados:

a) no que se refere aos erros conceituais: (i) a escolha marcante pelos professores da leitura do enunciado como ação didática faz pensar que, diferentemente de futuros 
DOI: http://dx.doi.org/10.20396/zet.v25i3.8649678

professores, para eles o erro pode ser derivado de uma incompreensão do enunciado e não ser apenas de natureza lógica; talvez devido à experiência, estejam eles atentos a este aspecto, a ser ressaltado na formação de professores; (ii) em comparação com o ocorrido com os professores, a forte opção pela explicação oral pelos futuros professores para os problemas de produto de medidas dá novamente sustentação à ideia de eles ainda sofrerem forte influência dessa forma mais tradicional de ensino em suas escolhas; (iii) em contraste, as escolhas mais salientes dos professores pela concretização para erros conceituais nos problemas de isomorfismo de medidas reforça a hipótese, acima esboçada, de que, em comparação com os futuros professores, para eles estaria mais sólida a ideia de que a compreensão pelo aluno das relações de proporcionalidade seria mais acessível pela manipulação de materiais, em contraste com a adoção da representação gráfica para os problemas de produto de medida;

b) no que se refere aos erros linguísticos, a escolha de representações gráficas e a da leitura do enunciado pelos professores, para problemas de isomorfismo de medidas, ao se sobreporem às escolhas tímidas dos futuros professores pela explicação oral e pela concretização, faz pensar nos limites que a formação profissional ainda em curso e a ausência de experiência profissional acarretariam para ser mais bem avaliada a importância dos aspectos linguísticos dos enunciados.

Porém, formação e experiência profissional podem perder sua força ao lembrarmos o quanto os dois grupos preferem representações gráficas para erros conceituais, no caso dos problemas de produto de medidas, porque assim melhor se configuram as combinações possíveis entre variáveis na solução desses problemas.

Sobre os sinais pouco claros que foram encontrados para a relação entre tipo de erro e ação didática, não haver sempre a escolha da leitura do enunciado para atender a erros linguísticos pode sugerir alguma inconsistência quanto a uma avaliação mais pertinente do que significaria um erro linguístico e sobre a importância de se interpretar com propriedade o enunciado de problema para corrigi-lo.

Pode-se argumentar, então que, professores e futuros professores, ao escolherem uma ação didática para corrigir um tipo determinado de erro, tenham recorrido à gama de conhecimentos sobre o ensinar, disponíveis em seu repertório de saberes, oriundo de vivências escolares, profissionais diversas, os quais nem sempre se manifestam estritamente organizados em teorias, posições pedagógicas sistematizadas. Governariam suas proposições, seu "saber fazer", suas teorias em ato, na acepção de Vergnaud (1996). E, nesse quadro, mais que o tipo de erro identificado e/ou a dificuldade específica do aluno, o tipo de problema de estrutura multiplicativa abordado parece bastante atrelado à escolha didática feita.

Em suma, formação e experiência profissional teriam lugar relevante nas escolhas didáticas para os erros discriminados, se combinados seus efeitos aos de outras particularidades da situação-problema (formas de solução, teor do enunciado). 
DOI: http://dx.doi.org/10.20396/zet.v25i3.8649678

Encerrando este texto, e privilegiando a formação docente em matemática como objeto de reflexão, pergunta-se: há, em geral, nessa formação elementos que propiciem uma atividade docente em que o erro fosse ferramenta didática? Evocariam os docentes ou futuros docentes razões ligadas a alguma teoria específica de aprendizagem? Ou suas manifestações apenas permitiriam antever a presença de teorias em ato em apoio às suas escolhas? Em caso afirmativo, que origem essas teorias em ato teriam? (Vergnaud, 1996). Dos resultados expostos, nada se pode adiantar a respeito, mesmo porque, nenhuma pergunta direta sobre o assunto foi feita aos participantes do estudo. Também, os dados do estudo não foram olhados com aquelas preocupações.

Enfim, o docente precisa necessariamente calibrar suas reflexões sobre suas possíveis ações didáticas conforme os diversos tipos de erro dos alunos em problemas matemáticos também diversos.

\section{Referências}

Astolfi, J. P. (1999). El "error", un medio para enseñar. Coleção "Investigación y Enseñanza”. Sevilha: Díada.

Bessot, A. (1980). Analyse d'erreurs dans 1'utilisation de la suite des nombres par les enfants de la lére. année de 1'énseignement obligatoire en France au cours préparatoire. In Proceedings of the International Congress on Mathematical Education, v. 4, (pp. 474476). Berkeley/CA: ICME 5.

Borasi, R. (1996). Reconceiving mathematics instruction: a focus on errors. Norwood, NJ: Ablex Publishing Corporation.

Borba, R., Pessoa, C. \& Rocha, C. (2012). How primary students and teachers reason about combinatorial problems. In ICMI-International Commission do MathematicalInstruction, (Ed.), 12th. International Congress of Mathematical Education: Pre-proceedings, (pp. 1795-1802). Seoul: ICMI.

Brousseau, G. (1998). Théorie des situations didactiques: didactique des mathématiques 1970-1990. Grenoble: La Pensée Sauvage.

Castro-Rodriguez, E., Rico, L. \& Gómez, P. (2012). Meanings of fractions as demonstrated by future primary teachers in the initial phase of teacher education. In: ICMIInternational Commission of Mathematical Instruction, (Ed.), 12th. International Congress of Mathematical Education: Pre-proceedings (pp. 1803-1810). Seoul: ICMI.

Chevallard, Y. (1985). La transposition didactique, du savoir savant au savoir enseigné. Grenoble: LaPensée Sauvage. 
DOI: http://dx.doi.org/10.20396/zet.v25i3.8649678

Contreras, L. C., Carrillo, J., Zakaryan, D., Muñoz-Catalán, M. C. \& Cliemtn, N. (2012). Um estúdio exploratório sobre las competencias numéricas de los estudiantes para maestro. BOLEMA, Rio Claro, 26(42B), 433-457.

Cury, H. N. (1994). As concepções de matemática dos professores e suas formas de considerar os erros dos alunos. Tese de Doutorado em Educação. Porto Alegre: UFRGS, Faculdade de Educação.

Cury, H. N. (2007). Análise de erros: o que podemos aprender com as respostas dosalunos. Belo Horizonte: Autêntica.

Fischer, M. C. B. (2008). Os formadores de professores de matemática e suas práticas avaliativas. In W. R. Valente (Org.), Avaliação em Matemática :histórias e perspectivas atuais (pp.75-100). Campinas, SP: Papirus.

Gitirana, V., Campos, T, M. M., Magina, S. \& Spinillo, A. (2014) Repensando Multiplicação e Divisão: Contribuições da Teoria dos Campos Conceituais. São Paulo: PROEM.

Koch, N. T. O. \& Soares, M. T. C. (2005). O professor, seus alunos e a resolução de problemas de estrutura aditiva. In M. L. F. Moro \& M. T. C. Soares (Orgs.), Desenhos, palavras e números: as marcas da matemática na escola (pp.145- 182). Curitiba: Editora UFPR.

Lakatos, I. (1976). Pruebas y refutaciones: la logica del descubrimiento matemático. Madrid: Alianza Editorial.

Margolinas, C. (1993). De l'importance du vrai et du faux: dans la classe de mathématiques. Grenoble: La Pensée Sauvage.

Moro, M. L. F. \& Soares, M. T. C. (2006). Aprendizagem de estruturas aditivas elementaresalunos, professores e pesquisadores como parceiros de uma construção conceitual. In M. R. F. de Brito (Org.), Solução de problemas e a matemática escolar (pp. 135-162). Campinas: Editora Alínea.

Pinto, N. B. (2000). O erro como estratégia didática: estudo do erro no ensino da matemática elementar. Campinas, SP: Papirus.

Spinillo, A. G., Pacheco, A. B. de, Gomes, J. F. \& Cavalcanti, L. (2014). O erro no processo de ensino aprendizagem da matemática: errar é preciso? Boletim GEPEM (Online), 64, 1-12. Disponível em http://dx.doi.org/10.4322/gepem2015.005

Spinillo, A., Soares, M. T., Moro, M. L. F. \& Lautert, S. F. (2016). Como professores e futuros professores interpretam erros de alunos ao resolverem problemas de estrutura multiplicativa? BOLEMA, 30(56), 1188-1206.

Vergnaud, G. (1983). Multiplicative structures. In R. Les \& M. Landau (Eds.), Acquisiton of Mathematics: Concepts and Processes (pp.127-174). London: Academic Press. 
DOI: http://dx.doi.org/10.20396/zet.v25i3.8649678

Vergnaud, G. (1996). Au fond de l'action, la conceptualisation. In J.-M. Barbier (Dir.), Savoirs théoriques et savoirs d'action (pp. 275-292). Paris: PUF.

Vergnaud, G. (2014). A criança, a matemática e a realidade. M. L. F. Moro, trad. ed. revisada. Curitiba: Editora UFPR. 


\section{APÊNDICE A: Problemas de produto de medidas}

Problema 1: Um parque de diversão tem 6 entradas (A, B, C, D, E, F) e 2 saídas $(1,2)$. Combinando as entradas e saídas, Daniela pode fazer caminhos diferentes para entrar e sair do parque. De quantas maneiras diferentes ela pode entrar e sair do parque?

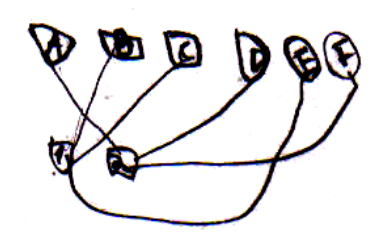

Problema 2: Pedro tem 3 camisetas (vermelha, amarela e verde) e 5 bermudas (marrom, laranja, preta, azul e branca). Ele quer combinar as camisetas e as bermudas para formar conjuntos. Quantos conjuntos diferentes ele pode formar?
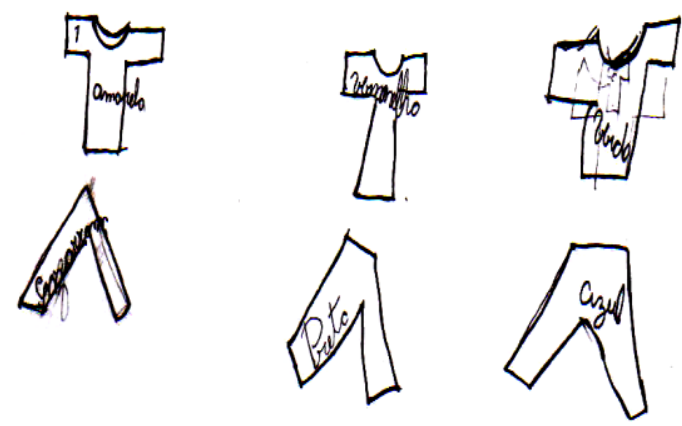

Problema 3: Combinando as blusas e as calças, Maria pode formar 20 conjuntos diferentes. O desenho abaixo mostra que ela tem 5 blusas. Quantas calças ela tem?
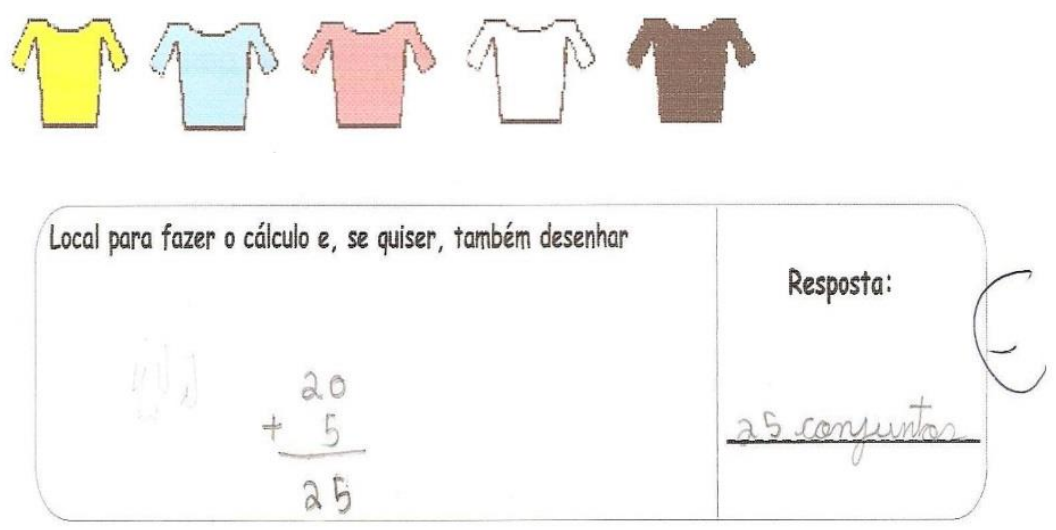


\section{APÊNDICE B: Problemas de isomorfismo de medidas}

Problema 4: Para ficar boa de uma doença, Ana tomou 32 comprimidos. O médico mandou Ana tomar 4 comprimidos por dia. Quantos dias este tratamento vai durar?

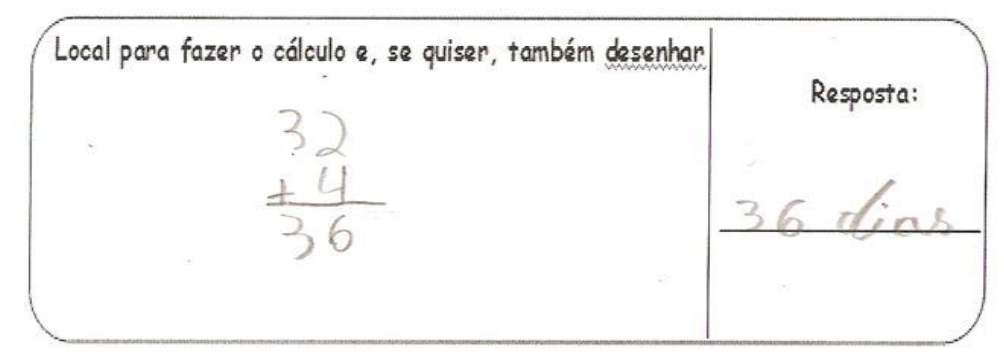

Problema 5: Uma floricultura vende caixas de jarros com flores. Cada caixa tem 6 jarros. Por sua vez, cada jarro vem com 2 flores. Sandra comprou 3 caixas. Quantas flores ela levou?

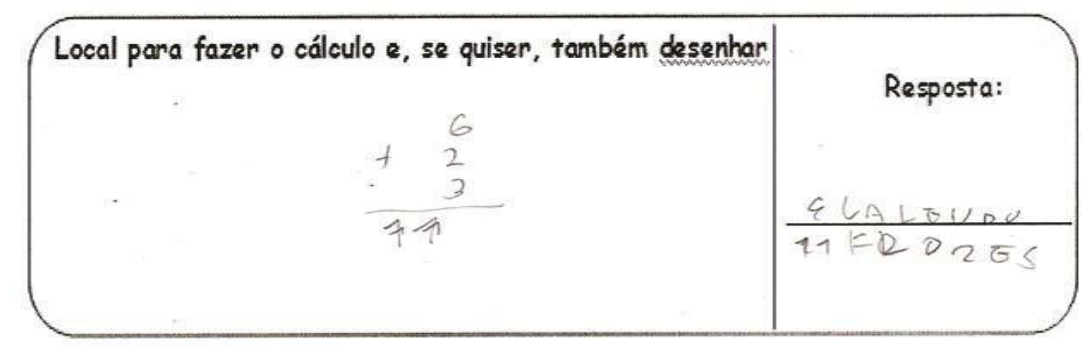

Problema 6: Dona Benta usa 15 ovos para fazer 3 bolos. Quantos ovos ela precisa para fazer 5 bolos?

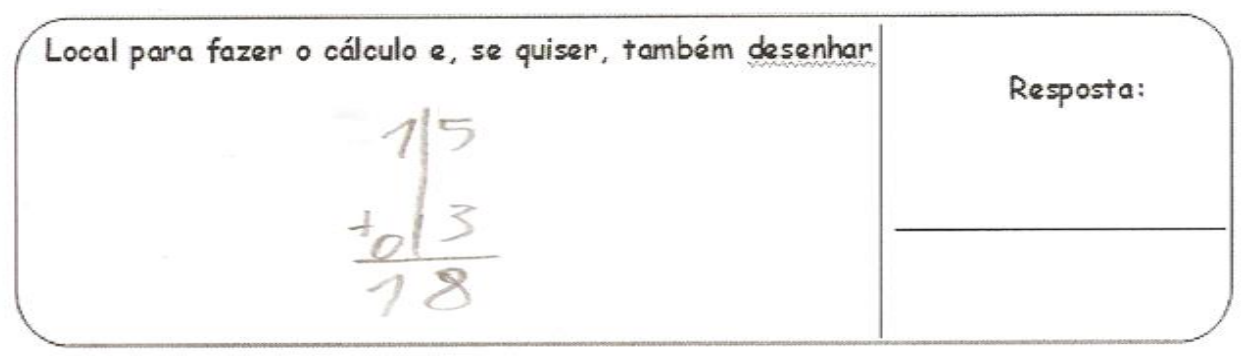

